\title{
Early Childhood Education Programs as Protective Experiences for Low-Income Latino Children and Their Families
}

\author{
Julia Mendez Smith ${ }^{1}$ (D) \\ Published online: 13 August 2020 \\ (C) Springer Nature Switzerland AG 2020
}

\begin{abstract}
Research is accelerating toward a deeper understanding of early childhood education (ECE) environments as protective experiences for Latino children; however, more work remains. This paper provides a review of the evidence that ECE environments benefit Latino children and mitigate the impact of adverse childhood experiences (ACEs) and other poverty-related risks; however, Latino families face numerous barriers to accessing ECE opportunities for their children. While enrollment by Latino children in ECE programs has grown in prior decades, further increases in access to ECE are needed to benefit Latino children, who are disproportionately impacted by poverty. In addition, ECE programs, especially high-quality and dual generation-focused programs like Early Head Start and Head Start, are in a strong position to help offset the risk for poor educational and mental health outcomes due to Latino's children's exposure to stressors such as discrimination and ACEs. Gaps remain in how well ECE is serving Latino families due to a combination of factors including parental work schedules, heritage language and cultural factors, and the lack of affordable and available ECE programs in Latino communities. To remedy these gaps, researchers must continue to further elucidate the needs, preferences, and gaps regarding access to early care and education opportunities for Latino children. For those studying trauma and ACEs among low-income children, greater attention to how preventative interventions or treatments that are embedded in ECE settings serve Latino populations is warranted, as this has the tremendous potential to mitigate the long-term impact of ACEs on Latino children. The paper concludes with a set of early childhood practice and policy recommendations for enhancing protective experiences for low-income Latino children.
\end{abstract}

Keywords Latino $\cdot$ Early childhood education $\cdot$ Resilience $\cdot$ ACEs $\cdot$ Project head start

Addressing the effects of adverse childhood experiences (ACEs) and the role of protective experiences in mitigating these effects is a critical need for low-income Latino ${ }^{1}$ children. While researchers are showing greater attention to this population, a long-standing, deficit view of Latino children has inhibited an evolution of the literature to reflect studies of the normative development and the resilience that often occurs in the context of high-poverty environments (Fuller \& Garcia, 2010). Use of a strengths-based perspective is essential for

\footnotetext{
${ }^{1}$ Latino is used in this paper to refer collectively to a heterogenous group of people in the USA consistent with the US Census definition of individuals with origins in Mexico, Puerto Rico, and Cuba, as well as other "Latino, Latino or Spanish" origins.
}

Julia Mendez Smith

jlmendez@uncg.edu

1 Department of Psychology, University of North Carolina at Greensboro, PO Box 26170, Greensboro, NC 27410, USA uncovering protective experiences that may help offset risk associated with Latino children's ACEs. To this end, this paper examines Latino children's involvement with early care and education programs $(\mathrm{ECE})^{2}$ with a specific focus on how ECE mitigates the impact of ACEs and provides important developmental experiences that help buffer children from ACEs and experiencing future associated negative outcomes. As evidence mounts regarding the importance of the early years on brain development and other formative milestones (National Research Council and Institute of Medicine, 2000; Shonkoff et al., 2012), including attachment and healthy relationships (Morris, Treat, Hays-Grudo, Chesher, Williamson, \& Mendez, 2018), oral language acquisition and vocabulary

\footnotetext{
${ }^{2}$ Early care and education (ECE) is an inclusive term that refers to all nonparental child care arrangements, including formal center-based programs and friend, family, or neighbor child care (home-based care). Home visitation services that are ongoing and educational for families are also included within the early care and education (ECE) term.
} 
growth (McNamara, 2016), and emotion regulation (Calkins \& Keane, 2009; Cohen \& Mendez, 2009), the expansion of ECE as a system to meet the developmental and mental health needs of low-income, at-risk populations has occurred. A careful analysis of ECE and the potential positive impacts of this experience for Latino children and their families will help move the field toward producing a greater evidence base for how ECE experiences are protective for low-income Latino children.

\section{Characteristics of Low-Income Latino Children}

As of 2018, about 1 in 4 of all US children are Latino and economic security is precarious for many (Child Trends, 2018; Federal Interagency Forum on Child and Family Statistics, 2014). Roughly $1 / 3$ of Latino children experience poverty, which amounts to about 5.7 million children, and is the highest rate of poverty for any US racial/ethnic minority group (DeNavas-Walt \& Proctor, 2015; Lopez \& Valasco, 2011). The vast majority (over $90 \%$ ) of Latino children in this country are US born (Murphey, Guzman \& Torres, 2014), meaning that they are eligible for means-tested assistance programs that are for citizen children. However, Latino households have some of the lowest utilization rates of these government assistance programs compared with other lowincome groups (Alvira-Hammond \& Gennetian, 2015), which means that these available benefits are failing to reach these vulnerable children. Lastly, many Latino children are growing up in households with immigrant parents and/or grandparents. Immigrant children and adults experience risk due to challenges or trauma experienced prior to, during and postmigration to the USA (Thibeault, Mendez, Nelson-Gray, \& Stein, 2017; Van Hook \& Glick, 2020). Estimates based on the US Census data show 1 in 4 Latino children has a parent who lacks authorization to reside permanently in the USA (Clarke, Turner \& Guzman, 2017). When immigrants feel unsafe in their communities, this further isolates children from resources, such as other adult and peer relationships as well as searching for and participating in ECE programs (Vesely, Goodman, Ewaida, \& Kearney, 2015; Yoshikawa, Kholoptseva, \& Suarez-Orozco, 2013).

There are a multitude of other characteristics that define Latino children in the USA such as their country of birth, parental countries of birth, US citizenship status, time in the USA, language spoken at home, English speaking proficiency, literacy, highest educational level attained outside of the USA, to name a few (U.S. Department of Health and Human Services, 2014). The Southeastern region of the USA, along with the Pacific Northwest and central US states, has experienced rapid, substantial growth in Latino households, making them new destination or emerging Latino communities
(Helms, Hengstebeck, Rodriguez, Mendez, \& Crosby, 2015; Lichter, Sanders, \& Johnson, 2015). Other states have historically been home to large numbers of Latino children for some time now, often referred to as established gateway communities (Lichter et al., 2015; Singer, 2008). When Latino populations are newer arrivals, receiving communities may lack the infrastructure to help them connect to employment, child care, and other resources (Turner, Wildsmith, Guzman, \& AlviraHammond, 2016). A study with immigrant mothers, many with origins in Central America, found that ethnic enclaves were a place where information was shared via social networks (Vesely et al., 2015). In the past few years, a reverse migration has also occurred where some Latino/Latino families, especially Mexican-origin families, are leaving the USA for their countries of origin, with reasons cited as challenging US economic and work opportunities, enforcement of US immigration laws, as well as a number of families endorsing family reunification as a reason to return to Mexico (Gonzalez-Barrera, 2015; Passel, Cohn, Gonzalez-Barrera, 2012). Taken together, the diversity of background of Latino children, as well as their tendency to experience high rates of poverty and/or trauma, must be considered in any examination of their participation in early care and education.

\section{Overview of the Paper}

This paper synthesizes the research on how participation in early care and education programs might serve as a critical protective factor for Latino children's development and mitigate their exposure to adverse childhood experiences (ACEs). Latino populations have been shown to have some of the highest rates of exposure to ACEs (Andrews, Haws, Acosta, Acosta Canchila, Carlo, et al., 2019; Ellis \& Dietz, 2017; Slopen, Shonkoff, Albert, Yoshikawa, Jacobs, Stoltz, et al., 2016). To guide the synthesis, a theoretical perspective is described which incorporates the sociocultural and transactional context that must be considered in examining ACEs among Latino children, their families, and ECE programs or providers. Next, this paper discusses the developmental and protective benefits that early care and education provides, focusing especially on the impacts that center-based early childhood education programs like Early Head Start and Head Start have had on reducing the impact of ACEs. Finally, this paper explores how well ECE programs and providers are serving Latino families by reviewing literature on the barriers and facilitators of ECE access and utilization for Latino households. The paper concludes with several recommendations intended to offset these obstacles in order to enhance the participation and reach of ECE as protective experiences for Latino children. 


\section{Sociocultural Theory and Transactional Framework}

As a backdrop for the review, existing sociocultural theory and ecological-transactional developmental frameworks illustrate how ECE can play a role in the development of Latino children (Bronfenbrenner \& Morris, 2006; Garcia Coll, Lamberty, Jenkins, McAdoo, Crnic, Wasik, et al., 1996; Masten \& Barnes, 2018; Mendez \& Westerberg, 2012). To best examine child development within a broader context, parental decisions about child care and use of government assistance must also be situated within a broader historical and contemporary socioecological context. Specifically, being of Latino and (even perceived) immigrant origin in the contemporary climate of the past decade with high attention and divisiveness in public, national discussions about immigration policy is a key context that impacts child development, families, and communities. In Garcia Coll and colleagues' (1996) Integrated Model for the Study of Developmental Competencies in Children of Color, a seminal framework for understanding minority child development in context, social stratification within society impacts the environments in which children and families live, attend school, and work. Furthermore, this model articulates that environments can either promote or inhibit children's development and will eventually influence how families socialize and share their cultural beliefs and practices to contribute to child outcomes. According to the theory, and supported by research, in promotive community environments, ECE programs can provide secure and enriching settings for Latino children, as well as support parent's need for work, and provide a social support network for immigrant families (Vesely et al., 2013). In contrast, neighborhoods and communities that feel unsafe or discriminatory may lead families to keep children at home as a proactive safety strategy (Bartlett \& Ramos-Olazagasti, 2018; Matthews et al., 2018) due to mistrust, and parents may limit their involvement in employment, use of programs, or other enrichment opportunities for the family (Brabeck, Sibley, Taubin, \& Murcia, 2016). Thus, the perceived unsafe environment serves as an inhibiting influence by limiting the reach of ECE and other services to Latino children.

Although significant numbers of Latino children use ECE, research continues to reveal the negative, and far-reaching, impacts of the present-day climate around immigration policy for Latino children and families (Van Hook \& Glick, 2020). Uncertainty stemming from changes to the federal definition of a public charge are reducing the likelihood of family participation in government assistance programs and impacting the decision-making process for families applying for benefits (Bernstein, Gonzalez, Karpman, \& Zuckerman, 2019). ECE providers are reporting negative impacts on enrollments and attendance as immigrant and Latino families report being less willing to separate from their children (Matthews et al., 2018).
This same study reported that ECE providers felt less equipped to support the needs of immigrant families, and they were struggling to connect the families to other community resources (Matthews et al., 2018). For these reasons, community-based organizations (CBOs) play a key role within communities to assist immigrants within communities to locate the resources they need, and to form connections with community groups that will help the family respond to pressures (Yoshikawa et al., 2013).

Figure 1 captures the range of influences on young Latino children and families. This model illustrates how the transactional relationships between and among families, ECE providers and programs, and community-based organizations weave together a stronger promotive environment that can serve as a deeper set of protective experiences for lowincome Latino children. Specifically, the bidirectional arrows signify the number of reciprocal interactions between members of the children's microsystem and exosystem contexts (Bronfenbrenner \& Morris, 2006). Poverty and the sociocultural context are part of a macrosystem influence which indirectly and directly impacts all the other levels of the ecology (Mendez \& Westerberg, 2012). Opportunities to mitigate the impact of ACEs during childhood occur within and across the other systems, such as home/family, ECE, and neighborhood/ community. Developing mutual connections that support children across the microsystems will serve to buffer the impact of ACEs on children.

\section{Overview of Adversity and Resilience in Latino Children}

An analysis of adversity and resilience requires examining how children's resilience emerges within a particular developmental context, as specific child characteristics transact with environmental influences to promote adaptation or recovery in the face of extreme adversity (Ellis \& Dietz, 2017; HaysGrudo \& Morris, 2020; Luthar, Cicchetti, \& Becker, 2000; Masten \& Barnes, 2018). In this section, we provide a review of some of the common and unique adverse childhood experiences encountered by Latino children in the USA. Although just $5 \%$ of the sample in the seminal research study on ACEs included Latino adults, they were represented in the highest prevalence of risk (11.2\% endorsed four or more categories of ACEs; Felitti, Anda, Nordenberg, Williamson, Spitz, Edwards, et al., 1998). Continued research on Latinos has documented the number of risks facing children, especially when they are born into high levels of poverty (Lichter, et al., 2015). Today, about $1 / 3$ of all Latino children are living in poverty, which dramatically increases the likelihood of exposure to ACES and often decreases the likelihood of reliable, easy access to mental health and other supportive services for children and their families. Particularly concerning are the 

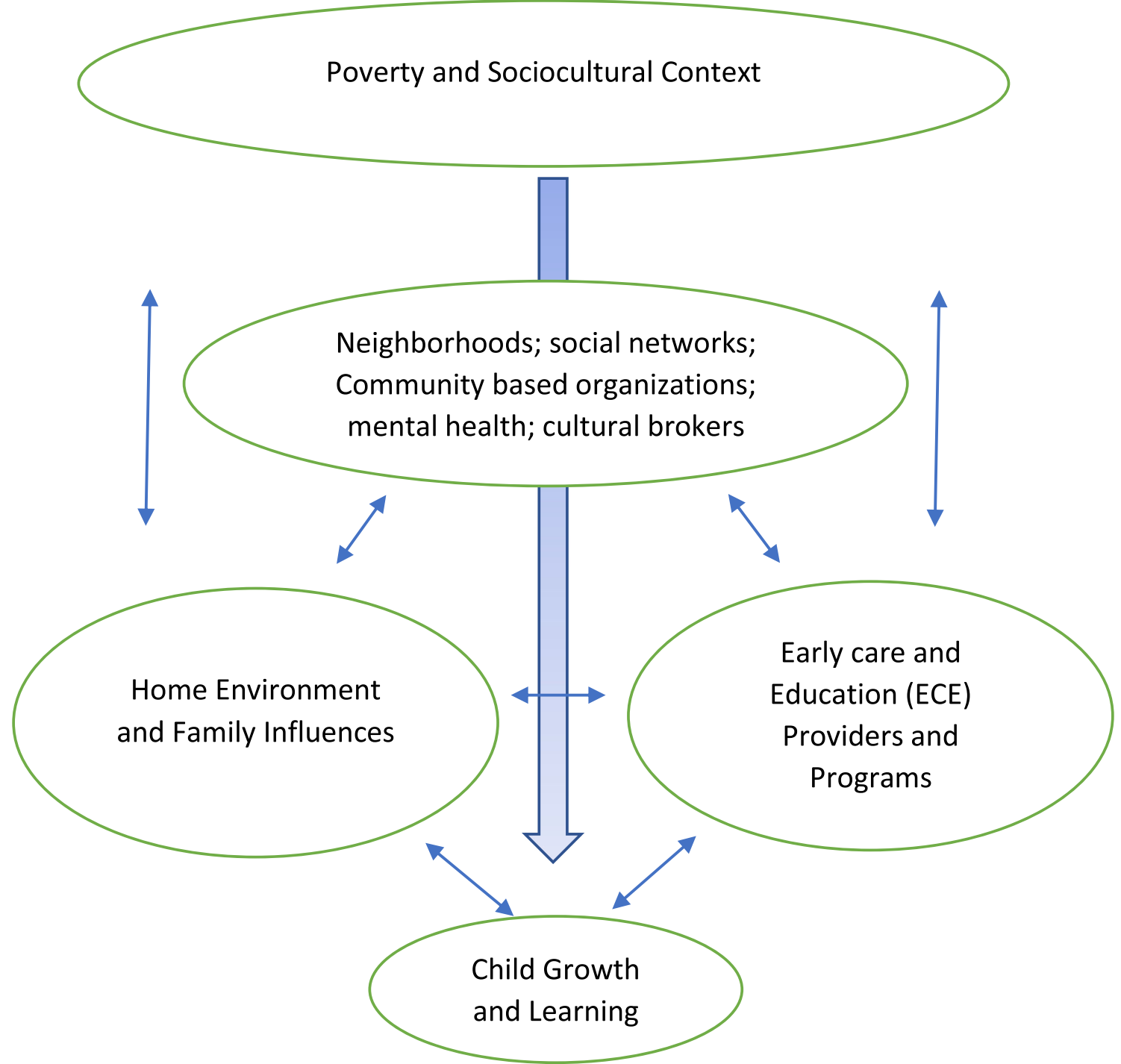

Fig. 1 Ecological transactional model for understanding how ECE and other supports may mitigate ACEs for low-income Latino children

highest rates of suicidality among Latina adolescents relative to other ethnic/racial groups (Zayes \& Pilat, 2008), which could be reduced by changing the negative trajectory from Latino ACEs to later mental health difficulties.

In addition to rates of poverty, work has shown the high rates of exposure to traumatic events and acculturative stress among recently arriving immigrant children (Thibeault et al., 2017). Other unpredictable stressors facing Latinos include economic uncertainty (Vesely, et al., 2015), immigration policy and harmful impacts on families (Yoshikawa, et al., 2013), and uncertainty regarding eligibility for services (AlviraHammond \& Gennetian, 2015). Discrimination faced by Latino youth themselves is also a cause for concern (Crosnoe, 2007; Gonzalez, Stein, Kiang, \& Cupito, 2014; Ramos-Olazagasti, Bird, Canino, \& Duarte, 2017). Finally, the practice of family separation occurring at the southern US border has caused major organizations that support child development to declare the traumatic separation of young children from their primary caregivers as a major assault on the attachment and security of developing Latino children (Bousa, Camacho-Thompson, Carlo, Franco, Garcia Coll, Halgunseth et al., 2018).

Latino rates of engagement in high-stress work situations also creates pressures on the family, which can have spillover effects onto the quality of the family-child experiences (Helms, Hengstebeck, Rodriguez, Mendez, \& Crosby, 2015; Sandstrom \& Huerta, 2013). Instability in the family is also created by Latinos employed in job sectors that include high rates of nonstandard work schedules (outside of M-F 9-5) where child care is less available, and workers receive little advance notice of their hours (Crosby \& Mendez, 2017). Job stress and low rates of health insurance among Latinos are found using national data, with only half of US-born Latino fathers and $35 \%$ of foreign-born Latino fathers having jobs offering employer-sponsored health insurance (Wildsmith, Ramos-Olazagasti, Alvira-Hammond, 2018). In a study of 
Latino migrant farmworkers, ACEs were related to higher exposure to harsh working conditions, and to larger effects of these harsh working conditions on depression and anxiety symptoms (Andrews et al., 2019). Taken together, all these factors create stress and uncertainty, which is a risk to the stability of the family unit and parent's mental health, which can compromise parents' ability to buffer their own children from ACEs.

\section{Benefits of ECE for Latino Children Exposed to ACEs}

For children who have directly experienced trauma early in life, ECE environments can provide safety and stability (Bartlett, Smith, \& Bringewatt, 2017; Paschall \& Mastergeorge, 2016). Traumas that young children face could have severe and early impacts on child development, due to the intense fear experienced or threat posed to the child's wellbeing (Lieberman, Chu, Van Horn, \& Harris, 2011). Therefore, ECE programs and providers are in a unique position to offer benefits to children experiencing trauma through (a) screening and detecting, (b) offering nurturing environments to offset or buffer from instability or ancillary effect due to the trauma, such as loss of a caregiver or witnessing domestic violence, and (c) supporting the family of the child who has experienced a trauma (Bartlett, et al., 2017), especially by connecting families to health or mental health resources. Because childhood adversities also co-occur (Hays-Grudo, 2020; Shonkoff et al., 2012), attending to the prevalence of traumatic exposure for children across different settings, particularly within Latino and immigrant communities facing high levels of discrimination (Ramos-Olazagasti et al., 2017), is paramount. The field is increasingly calling for a unified approach to reducing the exposure to ACEs among children and coordinated responses of systems, including ECE, child welfare, health care, education, and others, have been proposed as a way to mitigate the impact of toxic stress on the developing brain and disrupt pathways from early childhood trauma to future negative health and educational outcomes, particularly among minority populations (HaysGrudo, 2020; Lieberman et al., 2011; Shonkoff, et al., 2012).

To promote an understanding of how ECE contributes to resilience, let us turn to the evidence that ECE programs have a positive impact on low-income children who face adversity, including Latino children (Berlin, Martoccio, \& Jones Harden, 2018; Bitler, Hoynes, \& Domina, 2014; Crosnoe, 2007; Magnuson, Lahaie \& Waldfogel, 2006; Mendez, Crosby \& Siskind, 2018; Merritt \& Klein, 2015). For example, Early Head Start, a federal funded ECE program serving families of children under three, uses a range of delivery models across diverse communities including home-based services, center-based experiences, or a combination of settings to enhance parenting and child wellbeing. Early Head Start (EHS) has produced positive effects for children with adverse childhood experiences including maltreatment, homelessness, and families with mental health difficulties (Kane, Bailey, Wheat, \& Halle, 2020). Children participating in Early Head Start were less likely over time to be involved with the child welfare system, and the effects are in part driven by positive impacts of EHS on parenting including improved parent warmth with their child, lower parenting stress, and less conflict in the family (Green, Ayoub, Bartlett, Furrer, Chazen Cohen, Buttita et al., 2018). In a sample of low-income children (33\% Latino) involved with child welfare services who had a supervisory neglect status, language development was greater for children who experienced ECE settings as compared with those who did not (Merritt \& Klein, 2015). More generally, a significant benefit of home visitation programs are the repeated opportunities for screening children's ongoing exposure to ACEs, which permits more targeted supports and interventions to be offered to families (McKelvey, Conners Edge, Fitzgerald, Kraleti, \& Whiteside-Mansell, 2017).

In the first evaluation of an enhanced Early Head Start program model with a predominantly Latino sample $(87 \%)$, researchers compared two conditions: one intervention group receiving an EHS home-based program combined with the Attachment Biobehavioral Checkup (ABC; Dozier \& Bernard, 2017) which is an evidenced-based, parent-child attachment intervention, and the control group receiving an EHS home-based program combined with parents receiving a weekly book intervention. Parents who participated in the ABC intervention group plus EHS were rated by observers as significantly more sensitive/responsive, less intrusive, and higher on positive regard and overall sensitivity toward their infants than the Book-of-the-Week plus EHS control group (Berlin et al., 2018). The effect size for intrusiveness was large $(d=.77)$ which is a considerable positive step toward increasing the likelihood of a secure attachment (Berlin et al., 2018), as intrusive behavior among parents is alarming for infants and traumatic experiences for children often co-occur with traumatized parents (Lieberman, Chu, Van Horn, \& Harris, 2011). The ABC intervention was delivered by bilingual and trained parent coaches in the language of choice for parents, an adaptation that accounted for the linguistic diversity of the families. This research showed the value added of attachmentbased interventions, which is important as the original evaluation of the EHS impact did not find an effect on maternal supportiveness of children for Latino mothers (Raikes, Vogel, \& Love, 2013).

More generally, the literature also documents broad developmental benefits of ECE for Latino children, as well as other immigrant origin children (Votruba-Drzal, Coley, Collins, \& Miller, 2015). Specifically, ECE is a critical context for supporting the language, cognitive and social development, 
and growth for children who are dual language learners (DLLs; children who are learning two languages; McNamara, 2016). Evidence shows that when DLL students receive culturally relevant, high-quality instruction in English and Spanish and appropriate assessment of their emerging language abilities in both languages, early learning outcomes are optimized, and children can reap the benefits of being multi-lingual (Espinosa \& Garcia, 2012; Goldenberg, Nemeth, Hicks, Zepeda \& Cardona, 2013; National Academies of Science, Engineering \& Medicine, 2017). For other developmental outcomes, evaluations of ECE centerbased programs such as Head Start show greater than expected, positive impacts, from Latino and Spanish-speaking children's participation in ECE (Bitler et al., 2014; Crosnoe, 2007; Magnuson, Lahaie \& Waldfogel, 2006). A longitudinal study of children birth to five enrolled in Educare programs found that dual language learner children showed greater gains in receptive vocabulary relative to English speakers, and that effects for children entering the program at earlier ages were stronger, although children entering for only a year or two made rapid gains, suggesting that early entry in ECE has benefits for dual language learners (Yazejiana, Bryant, Freel, Burchinal, and the Educare Learning Network (ELN) Investigative Team, 2015). In terms of school readiness skills for immigrant children, research found use of subsidized center-based care was linked to children's early reading skills, possibly due to exposure to print materials and language stimulation in classrooms (Johnson, Ruhm, Wen-Jui, \& Waldfogel, 2014). Lastly, research found long-term associations showing Latino children enrolled in public school pre-K scored higher on standardized tests of math and literacy during third grade than children in subsidized center-based care (although Head Start centers were excluded from this research), after controlling for baseline characteristics and preschool entry skills (Ansari, López, Manfra, Bleiker, Dinehart, Hartman et al., 2017).

Finally, we have examples of improvement in culturally congruent service delivery across ECE programs serving young Latino children and their families. Research has shown that when cultural adaptations are made to existing preventive interventions for Latino families, outcomes are generally positive (Beasley, Silovsky, Espeleta, Robinson, Hartwig, Morris et al., 2017; Griner \& Smith, 2006; Mendez \& Westerberg, 2012). For example, a study of the Legacy for Children ${ }^{\mathrm{TM}}$ parenting program, which previously showed evidence of effectiveness with English-speaking Latino families, also found that Spanish-speaking parents were able to participate after translation of intervention content and cultural adaptations (e.g., adding recordings of traditional, familiar songs, using Spanish-speaking, Latino recruiters) were made (Beasley et al., 2017). In an embedded parenting intervention within Head Start programs, cultural adaptations to The Companion Curriculum, including providing bilingual facilitators,
Spanish-translations, opportunities for practicing English conversation skills, and holding sessions multiple nights a week, was effective in facilitating participation by Spanish-speaking parents with low levels of acculturation to the USA (Mendez $\&$ Westerberg, 2012). These studies show the continued importance of incorporating culture and language adaptations into ECE programs that work with parents, especially to maximize the impact of their interventions.

\section{Barriers and Facilitators of ECE Utilization by Low-Income Latino Children and Families}

Given the benefits of ECE as a protective experience, what do we know about Latino children and how their participation in ECE is changing over time? Throughout this review, and across the field, we are using the term ECE to encompass a wide array of non-parental child care options and programs, which may occur across different settings (home or center) as well as for variable number of hours, often while parents work (Crosnoe, 2007; Gennetian, Datta, Goerge, Zanoni, Brandon, Witte, \& Krishnamurty, 2019). For Latino children, long-held beliefs that their families were not interested in using nonparental care for their children are likely less true today, as alternative explanations in the data are coming to light (Ackert, Ressler, Ansari, \& Crosnoe, 2018; Mendez et al., 2018). With the inclusion of larger numbers of low-income Latino children in nationally representative data sets (e.g., National Study for Early Care and Education; NSECE, 2012), we are now able to look at within group variation in families' use of ECE and how it serves to support children's overall development. The findings suggest that gaps in ECE participation by Latino families are closing relative to White and Black peers (Crosby, Mendez, Guzman, \& Lopez, 2016) with about $53 \%$ of Latino families using non-parental care for their preschool child. In 2016-2017, 38\% of children enrolled in Head Start were Latino, with 35\% percent of children enrolled in Early Head Start from a Latino background (Child Trends Databank, 2018).

Families in the USA endorse their top reason for using nonparental child care is to support their desire to work (Gennetian et al., 2019), and this is also true for low-income Latino households. For example, using the NSECE (2012), researchers found that $44 \%$ of low-income Latino families endorsed "so I can work or changes to my work schedule" as a primary reason for searching for an ECE provider or program. Second, a second important reason for use of ECE was to "provide child enrichment or social enrichment", with $29 \%$ selecting this reason to search for care (Mendez \& Crosby, 2018). Examining the search process revealed another layer in inequity for low-income Latino households. Using these same NSECE (2012) data, researchers found that lowincome Latino parents reported conducting significantly fewer 
numbers of searches during the prior 24 months and considered fewer providers (Mendez \& Crosby, 2018).

Unfortunately, studies continue to document a lack of equity for Latinos across diverse ECE programs (Harding \& Paulsell, 2018). For federally subsidized child care (provided by the Child Care Development Fund; CCDF), the rate of utilization among Latino families is lower than among their non-Latino peers. While Latino children are $35 \%$ of the CCDF-eligible population, just $20 \%$ of those receiving CCDF benefits are Latino (U.S. GAO, 2016). In an analysis of Head Start participation, Latino children fare slightly better and with $38 \%$ participation rate compared with $54 \%$ of African American children and $43 \%$ of all eligible lowincome children (Schmit \& Walker, 2016). This same report conducted a state level analysis and showed that 6 of the 10 states (SC, GA, NC, TN, FL, AL) with the lowest success in serving Latino children in Head Start were in the Southern USA (Schmit \& Walker, 2016). In a study of the 13 states serving the highest numbers of low-income Latino children, researchers found a number of administrative burden requirements, such as required documentation or English-only applications, that likely served as barriers to applying for and becoming eligible for CCDF subsidies for child care (Hill, Gennetian, \& Mendez, 2019).

Even accounting for all possible ECE arrangements, including family, friend and neighbor care, and center care arrangements, disparities for Latinos persist. In a national study using 2012 data from the NSECE (2012), comparisons showed that gaps between utilization rates for low-income white $(56 \%)$ and Latino preschool age children $(53 \%)$ are narrowing (Crosby et al., 2016). However, there remain wide gaps in enrollment for infants and toddlers by race/ethnicity. Use of ECE centers is around 15-18\% for low-income Latino and white infants and toddlers, compared with $26 \%$ for lowincome African American infants and toddlers (Crosby et al., 2016). This gap is critically important to better examine, as center-based care tends to be of a higher quality and more impactful for developmental and learning outcomes for lowincome children than other care (Zaslow, Crosby \& Smith, 2013). More research is also needed regarding the impact of home and neighbor care, given that these arrangements are used with greater frequency for infants and toddlers (Crosby et al., 2016).

The child care accommodation model offers an explanation (Hill et al., 2019; Weber, 2011) of how parental access to care requires a series of decisions and tradeoffs for the family to consider in locating and using a child care arrangement. Generally, parents are looking for quality and affordable child care that meets their employment and other family needs, including developmental benefits for the child (Friese, Lin, Forry, \& Tout, 2017). Consistent with Garcia Coll's (1996) model identifying the promoting and inhibiting factors that influence minority child development (described earlier), the child care accommodation model also emphasizes that decisions of the family do not occur in an individual context; rather, families must consider the multiple needs and community/contextual factors that may impact the development of their child (Mendez et al., 2018). For example, even though $90 \%$ of children under 10 are US born (Murphey et al., 2014), the climate surrounding families who are immigrants to this country may have a negative impact on families seeking resources from government sources of assistance (Bernstein, et al., 2019; Vesely, Ewaida, \& Kearney, 2013).

Characteristics of low-income Latino households and work reveal how child care may not be meeting the needs of families. First, low-income Latino families are more likely to be married and reside in two-parent households, with a high rate of dual parental employment (Mendez et al., 2018; Wildsmith et al., 2018). This means that although children have access to multiple caregivers, juggling work schedules and child care arrangements can be challenging. In addition, Latino employment tends to occur during non-standard working house (outside of M-F 9-5) at higher rates than other low-income populations (Crosby \& Mendez, 2017), with a national study finding that over $3 / 4$ of low-income Latino children with a working parent have a least one parent working nonstandard hours (Crosby \& Mendez, 2017). This is problematic as most formal child care arrangements, especially centerbased arrangements including Head Start, do not support care during non-standard hours, leaving parents to find informal arrangements. Lastly, somewhat counter to prior observations about who cares for young children, Latino families report lower availability of a relative to provide care for a child than their White and African American peers (Guzman, Hickman, Turner, \& Gennetian, 2016). A barrier for entry into ECE programs or obtaining quality child care is that families who need care may be unsuccessfully searching for providers or programs that also accommodate non-standard work schedules.

Finally, instability and stress associated with work among low-income families, including Latino families, provide a stressor on the family and complicates locating child care that is available and affordable. One study found that roughly half of low-income Latino working parents receive short advance notice of work hours (i.e., 1 week or less), with higher rates reported by immigrant households (Crosby \& Mendez, 2017). This type of scheduling likely makes planning for and maintaining care arrangements difficult, especially with providers that offer less flexible care and payment options. Using multiple providers may be more costly, and recent estimate shows that while that about 6 in 10 low-income Latino households report using some type of free child care, 4 out of 10 families have costs that exceed $7 \%$ of the household budget, which has been cited in recent government guidelines as a reasonable target to spend for ECE (Crosby, Mendez \& Barnes, 2019). Work-related risk also creates challenges to provide nurturing 
environments, when adults who were exposed to ACEs now struggle with their own wellbeing (Andrews et al., 2019).

In sum, barriers for low-income Latino families to access care include lack of awareness, lack of affordable options, or inability of providers/programs to support work schedules of Latino families. Given the high prevalence of non-standard work hours, and instability in work schedules, these factors will complicate parents securing arrangements for their children. Additionally, there are opportunities to increase the potential for ECE to meet the needs of these families. Currently, low percentages of infants and toddlers are enrolled in centerbased care, which would provide low-income Latino children with greater access to screenings and services that are effective in promoting positive parenting and child well-being (Berlin et al., 2018).

\section{Looking Forward: Including Latino Family and Community Assets Within ECE Settings}

A critical need in addressing the prospective resilience of Latino children is to begin to help practitioners and researchers examine a more robust inventory of compensatory factors. These family and community assets are also likely key influences (alongside the reviewed impacts of ECE on children exposed to ACEs) more generally on the development of all Latino children (Fuller \& Garcia Coll, 2010; Masten \& Barnes, 2018). Researchers continue to recommend use of a within-group and strengths-based perspective on child development, as there is a preponderance of risk studies of communities of color, including Latino communities, and less data on the protective factors or strengths of the families and communities (Cabrera, Beeghly \& Eisenberg, 2012; Fuller \& Garcia Coll, 2010). For example, asset-based approach has uncovered protective factors among Latinos including high rates of marriage and stable unions for child rearing (Murphey et al., 2014), parental investments in children for a better life (Helms et al., 2015), language inputs (Hammer, Rodriguez, Lawrence, \& Miccio, 2007), and high levels of workforce participation (Wildsmith, Ramos-Olazagasti \& AlviraHammond, 2018). In this section, we review some of the literature on assets within Latino families that may play an important role in combination with ECE programs to buffering Latino children and their families from the impact of ACES.

Family and Parenting Assets to Offset Risk Attitudes about education and importance of respect and deference to educators have been examined as assets within Latino families. For example, Fuller and Garcia Coll (2010) review cultural values for Latino families that have been included in empirical studies such as bien educado (Reese, Balzano, Gallimore, \& Goldberg, 1995), the idea of raising a child with good manners, and respeto, which emphasizes obedience and children should not argue with adults (Calzada, Fernandez, \& Cortes, 2010). Familismo is another cultural value that suggests obligations to the family and use of the family as a primary social support and reference for guiding one's behavior (Stein, Cupito, Mendez, Prandoni, Huq, \& Westerberg, 2014). In their review, Halgunseth et al. (2006) describe Latinos as having an "interdependent orientation," (p. 1282). Their paper argues that Latino parental control derives from attributions made about the importance of instructing the child in appropriate and inappropriate ways of interacting with other children and adults, in support of cultural values such as familism and respeto (Halgunseth, Ispa, \& Rudy, 2006).

Other examples of parental knowledge and intentional behavior include simultaneous language development of bilingual children (Hammer et al., 2007), high levels of children's social competence at kindergarten entry (Galindo \& Fuller, 2010), and unique, child-focused sociocultural patterns of family engagement during early childhood (McWayne, Melzi, Limlingan, \& Schick, 2016). Consistent with the beliefs about the value of education among Latinos, a study using the ECLS-K by Crosnoe \& Kalil (2010) found that Mexican immigrant mothers who were involved in their own schooling showed increased engagement with their children over a 4-year period, suggesting that changes in educational attainment, regardless of degree attainment, impact child development. This work is consistent with researchers who have concluded the value of two-generation (e.g., child and family) early intervention model for working with Latino families, due to the interconnected nature of family members and the need for increased education and learning opportunities for both parents and children (Crosnoe \& Kalil, 2010; Mendez \& Westerberg, 2012).

Community Level Factors that Impact Latino Parenting The economic choices facing a family create both assets or reduced risk, as for example, work showing that low-income Latinos reside in higher income neighborhoods, perhaps as a strategy for reducing ACEs associated with residing in poor neighborhoods (Fuller \& Garcia Coll, 2010). In contrast, negative community experiences and attitudes toward immigrants may lead parents to become more isolated and less trusting toward systems seeking to offer resources for Latino children, including government assistance (Vesely et al., 2013). This also increases pressure on ECE providers to reach the most vulnerable families within communities (Matthews, Ulrich, \& Cervantes, 2018). Studies of interventions designed to reach immigrant Latino families found that increasing communication between ECE providers in Head Start centers and parents led to higher parental involvement and home, school, and in parent-teacher conferences (Mendez, Westerberg \& Thibeault, 2013); however, efforts to encourage parents to enroll in language classes at a local community college failed 
due to lack of trust of outsiders (Mendez \& Westerberg, 2012). Examining community density of child care center and Latinos, researchers found that as the density of both supply in a county increased, so did enrollment, and that increased Latino density mattered after controlling for supply, suggesting that social networks in ethnic enclaves for Latinos is an important strategy for building connections to programs (Ackert, et al., 2018).

In sum, while research has been accelerating toward a deeper understanding of ECE environments as protective experiences for Latino children, more work remains. For researchers, it is a now a question of intentional inclusion of promoting influences or protective factors in studies, so we can better understand constructs like social ties among Latino communities (Ackert et al., 2018), parenting strengths including attitudes and practices (Calzada et al., 2010; Crosnoe \& Khalil, 2010), and relationships between families and ECE providers (Mendez \& Westerberg, 2012) that offer important assets to children as they enter ECE programs. We should continue also help practitioners better understand the needs, preferences, and gaps involving in meeting the needs of Latino families through professional development opportunities and pre-service teacher preparation programs. The design of our longitudinal and national data collection efforts must better reflect the diverse characteristics of this heterogeneous population of children and their families (Guzman, RamosOlazagasti, Miller, Padilla, Ryberg, \& Vega, 2018). For those studying trauma and ACEs among low-income children, increasing familiarity with the Latino community and factors driving ECE utilization, economic uncertainty, and family instability will be important areas for integration within research studies. Finally, preventative interventions and treatments that can be offered through ECE settings (Berlin et al., 2018) or through partnerships with health care delivery systems should be investigated, as Latinos continue to experience incidents of trauma, ongoing discrimination, and other poverty-associated risks (Andrews et al. 2019; Ramos-Olazagasti et al., 2017).

\section{Implications for Enhancing Early Childhood Practice and Policy for Latino Children}

This paper concludes with a set of priorities for the field to consider for enhancing early childhood practice and policy for Latino children. These are particularly timely to consider, given that the USA is experiencing an unprecedented threat to the child care sector associated with tremendous job loss and closures of programs during the Covid-19 pandemic (Zero to Three, 2020). There is also emerging evidence that Latino families are currently experiencing significant unsafe work risks (Genettian \& Johnson, 2020), making the future engagement with ECE programs even more critical to buffer children from the poverty-associated stressors in their homes and neighborhoods, as well as to detect ACEs and offer services for parents. An effective response will require sustained and increased investment in early care and education resources and services in the following areas:

1. Prepare and Train a Diverse ECE Workforce. The ECE workforce must be prepared to work more effectively with diverse groups of families, particularly Latino immigrants with high levels of ACEs exposure. The quality of ECE is highly dependent on the resources and training given to ECE providers. Improving the quality of ECE for young children can occur, for example, through implementation of evidence-based parenting programs, home visitation, and the provision of access to specialists who assist families with children's health, educational, and developmental needs. As ECE expansion occurs, programs that encourage training and certification of providers from culturally diverse and multi-lingual backgrounds will ensure that our future ECE workforce keeps pace with the current diversity of our immigrant and Latino child populations. Specific training for how to work with culturally and linguistically diverse families can better support ECE providers who will be increasingly working with these families. Training in approaches for culturally relevant teaching methods for working with dual language learners and their families (McNamara, 2016) will increase children's' ability to community and express their feelings. Also, expanding access to information and trainings on ACEs, better recognition of the stressors associated with living in an immigrant community, and use of principles of traumainformed care will help with teacher preparation and readiness to serve vulnerable families well. This should occur at the teacher preparation level and as on-going professional development for teachers and within the quality improvement process for ECE programs.

2. Routinely Identify ACEs within ECE Settings to Inform Service Delivery. Through ECE developmental screenings, community partnerships with mental health providers, and mechanisms for building safety and trust networks, particularly in communities with recently arriving immigrants in new destination communities, ECE is poised to make an impact on reducing the impact of ACEs and other stressors for Latino children and families. The timing of these interventions matter (Masten \& Barnes, 2018), as early identification and intervention can offset future, and worsening, outcomes (Morris et al., 2018; Shonkoff et al., 2012). Training for providers in trauma-informed approaches to care, including recognition of emotional and behavioral signs of distress among Latino children, is needed (Bartlett \& RamosOlazagasti, 2018; Bartlett, Smith, Bringewatt, 2017). Inclusion of evidence-based attachment interventions in ECE settings serving Latino families is supported to 
improve maternal supportiveness and increase children's secure attachments with caregivers (Berlin et al., 2018). We need greater attention to these issues among our researchers studying ACEs among Latino samples, particularly those with ongoing longitudinal studies, as well as national data to inform rates of ACEs and association poverty-related traumatic events. This will allow a more complete picture of the needs and assets to emerge, in order to understand what is working to offset the risk of ACEs and other trauma experienced in early childhood.

3. Build Community and Provider Networks to Better Serve Latino Families. The community context plays a key role in supporting low-income Latino families, especially to combat social isolation and help link families with ECE. When families feel less welcome and safe in particular communities, this can have a chilling effect on families seeking services (Matthews et la., 2018; Vesely et al., 2013). ECE providers/agencies are in a good position to provide outreach and support for low-income Latino family members and/or children are experiencing stress or trauma, with appropriate training (Matthews, et al., 2018). The density of Latinos in a community has been associated with greater use of ECE, after controlling for supply, and so building social ties among members of a Latino community may increase utilization (Ackert et al., 2018). However, Latino parents may need greater assistance in locating ECE programs and understanding benefits they may provide to children, given the lower rates of searches by Latino households relative to other low-income groups (Mendez \& Crosby, 2018). Cultural brokers embedded within community-based organizations often can provide families (particularly immigrant families who are recently arriving or with households with undocumented adults) with appropriate referrals and community supports (Yoshikawa, Kholoptseva, \& SuarezOrozco, 2013). Lieberman et al. (2011) note that most traumatized children are not found in mental health clinics; rather, they are more routinely seen in child care and health care settings. Thus, community partnerships that connect ECE with other sectors serving vulnerable children, including housing, pediatrics, child welfare, and non-profits addressing domestic violence and homelessness, are also needed to create community resilience and offset the toxic stress that comes from high exposure to ACEs (Ellis \& Dietz, 2017).

4. Increase Access to Affordable and Available ECE for Latino parents. Significant gaps exist in the ability of ECE, particularly center-based programs, to reach and meet the need for ECE among Latino families (Mendez, 2018). No-cost federal programs for low-income children including Head Start and Early Head Start do not have the capacity to serve all eligible Latino children. Enrollments of Latino children are $38 \%$ participation rate compared with $54 \%$ of African American children and $43 \%$ of all eligible low-income children, and enrollment in the South is low relative to the increases of the population in this region (Schmit \& Walker, 2016). Moreover, given the high prevalence of families who work non-standard schedules (Crosby \& Mendez, 2017), policies that encourage flexibility in ECE timing and available hours may be particularly useful for Latino parents with irregular (variable) work schedules, as well as those enrolled in adult education programs, which often take place during evenings or weekends. The cost of child care is a top concern among this population, as well as other lowincome groups, with a recent analysis showing 4 out of 10 low-income Latinos reporting child care costs that exceed government-recommended guidelines of $7 \%$ of the total household budget (Crosby, Mendez \& Barnes, 2019). Therefore, policies that encourage provider outreach to Latino families or consumer education to help them locate affordable care are needed. Continued public investments in ECE that increase supply and lower the cost of care for low-income Latino families are also needed.

\section{Conclusion}

This paper offers a roadmap for future work investigating the assets and risk facing low-income Latino children in the USA. As we face a new economic downturn associated with the onset of the Covid-19 pandemic, our most vulnerable families will require sustained and careful monitoring to ensure that children are protected. We must be mindful of the consequences of the economic recession for Latino workers, who are overrepresented in many of the hardest hit industries and jobs. Also, without a resurgence of investment in child care, workers will be unable to secure positions that allow them to provide economic support for their families. High levels of stress and exposure to violence, as well as continued bias and discrimination against Latino populations and other immigrant groups, will constitute some of the most formidable adverse childhood experiences for our young and vulnerable children. Providing robust, affordable, and inclusive early care and education opportunities, with the additional supports and services for addressing trauma, are essential investments we can and must take as we look toward building resilience. To turn away from these challenges facing Latino families will result in future morbidity, mental health challenges, and negative educational and economic impacts for decades into the future.

Acknowledgment I would like to acknowledge and thank Danielle Crosby for her collaboration and work to produce new findings about 
ECE and Latino children, along with all my collaborators at the National Research Center on Hispanic Children and Families.

Funding Information This paper was supported in part by grant \#90PH0028 from the Office of Planning, Research and Evaluation within the Administration for Children and Families in the US Department of Health and Human Services.

\section{References}

Ackert, E., Ressler, R., Ansari, A., \& Crosnoe, R. (2018). Community contexts and utilization of early childhood care and education among Mexican-origin children. Early Childhood Research Quarterly, 52, 4-14. https://doi.org/10.1016/j.ecresq.2018.09.008.

Alvira-Hammond, M. \& Gennetian, L.A. (2015). How Latino parents perceive their need and eligibility for public assistance. Retrieved from https://www.Latinoresearchcenter.org/wp-content/uploads/ 2019/08/Income-Brief-No.-2-Perceptions-of-Eligibility-V21.pdf

Andrews III, A. R., Haws, J. K., Acosta, L. M., Acosta Canchila, M. N., Carlo, G., Grant, K. M., \& Ramos, A. K. (2019). Combinatorial effects of discrimination, legal status fears, adverse childhood experiences, and harsh working conditions among Latino migrant farmworkers: Testing learned helplessness hypotheses. Journal of Latinx Psychology., 8, 179-201. https://doi.org/10.1037/lat0000141.

Ansari, A., López, M., Manfra, L., Bleiker, C., Dinehart, L. H., Hartman, S. C., \& Winsler, A. (2017). Differential third-grade outcomes associated with attending publicly funded preschool programs for lowincome Latino children. Child Development, 88, 1743-1756.

Bartlett, J. D., \& Ramos-Olazagasti, M. A. (2018). Supporting children and parents affected by the trauma of separation. Bethesda, MD: National Research Center on Latino Children \& Families. from http://www.Latinoresearchcenter.org/publications/supportingchildren-and-parents-affected-by-the-trauma-of-separation/.

Bartlett, J.D., Smith, S., Bringewatt, E. (2017). Helping young children who have experienced trauma: Policies and strategies for early care and education. Child Trends. Retrieved online from https://www. childtrends.org/publications/ecetrauma

Beasley, L. O., Silovsky, J. F., Espeleta, H. C., Robinson, L. R., Hartwig, S. A., Morris, A., \& Esparza, I. (2017). A qualitative study of cultural congruency of legacy for children ${ }^{\mathrm{TM}}$ for Spanish-speaking mothers. Children and Youth Services Review, 79, 299-308. https://doi.org/10.1016/j.childyouth.2017.06.022.

Berlin, L. J., Martoccio, T. L., \& Jones Harden, B. (2018). Improving Early Head Start's impacts on parenting through attachment-based intervention: A randomized controlled trial. Developmental Psychology, 54, 2316-2327. https://doi.org/10.1037/dev0000592.

Bernstein, H., Gonzalez, D., Karpman, H., \& Zuckerman, S. (2019). One in seven adults in immigrant families reported avoiding public benefit programs in 2018. Retrieved online from https://www.urban. org/sites/default/files/publication/100270/one_in_seven_adults_in immigrant_families_reported_avoiding_publi_8.pdf

Bitler, M.P., Hoynes, H.W., \& Domina, T. (2014). Experimental evidence on distributional effects of Head Start. NBER Working Paper No. w20434. Cambridge, MA: National Bureau of Economic Research. Retrieved from: http://www.nber.org/ papers/ w20434.

Bousa, J., Camacho-Thompson, D., Carlo, G., Franco, X., Garcia Coll, C., Halgunseth, L.C., Marks, A., Stein, G.L., Suarez-Orozco, C., \& White, R. (2018). The science is clear: Separating families has longterm damaging psychological and health consequences for children, families, and communities. Society for Research in Child Development.
Brabeck, K. M., Sibley, E., Taubin, P., \& Murcia, A. (2016). The influence of immigrant parent legal status on US-born children's academic abilities: The moderating effects of social service use. Applied Developmental Science, 20(4), 237-249.

Bronfenbrenner, U., \& Morris, P. A. (2006). The bioecological model of human development. In R. M. Lerner \& W. Damon (Eds.), Handbook of child psychology: Theoretical models of human development (p. 793-828). John Wiley \& Sons Inc.

Cabrera, N. J., Beeghly, M., \& Eisenberg, E. (2012). Positive development of minority children: Introduction to the special issue. Child Development Perspectives., 6, 207-209. https://doi.org/10.1111/j. 1750-8606.2012.00253.x.

Calkins, S., \& Keane, S. P. (2009). The developmental origins of antisocial behavior. Development and Psychopathology, 21, 1095-1109. https://doi.org/10.1017/S095457940999006X.

Calzada, E. J., Fernandez, Y., \& Cortes, D. E. (2010). Incorporating the cultural value of respeto into a framework of Latino parenting. Cultural Diversity and Ethnic Minority Psychology, 16, 77-86.

Child Trends (2018). Racial and ethnic composition of the child population. Retrieved from https://www.childtrends.org/indicators/racialand-ethnic-composition-of-the-child-population.

Child Trends Databank. (2018). Head start. Retrieved online at https:// www.childtrends.org/?indicators=head-start

Clarke, W., Turner, K., \& Guzman, L. (2017). One quarter of Latino children in the United States have an unauthorized immigrant parent. In National Research Center on Latino children and families Retrieved from https://www.Latinoresearchcenter.org/wp-content/ uploads/2019/08/Latino-Center-Undocumented-Brief-FINAL-V21. pdf.

Cohen, J. S., \& Mendez, J. L. (2009). Emotion regulation, language ability, and the stability of preschool children's peer play behavior. Early Education and Development, 20(6), 1016-1037. https://doi. org/10.1080/10409280903430745.

Crosby, D. \& Mendez, J.L. (2017). How common are nonstandard work schedules among low-income Latino households with young children? National Research Center on Latino Children and Families. Brief 2017-50. http://www.Latinoresearchcenter.org/wp-content/ uploads/2017/11/Latinos-Center-parental-work-hours-Brief-11.1. pdf

Crosby, D. A., Mendez, J. L., Guzman, L., \& López, M. (2016). Hispanic children's participation in early care and education: Type of care by household nativity status, racelethnicity, and child age. Washington, DC: The National Research Center on Hispanic Children and Families. Retrieved online at http://www. hispanicresearchcenter.org/wp-content/uploads/2016/11/201659HispECEType.pdf.

Crosby, D., Mendez, J., \& Barnes, A. (2019). Child care affordability is out of reach for many low-income Latino households. Bethesda, MD: National Research Center on Latino Children and Families https://www.Latinoresearchcenter.org/wp-content/uploads/2019/ 10/Latino-Center-Child-Care-Affordability-October-2019-FINAL . pdf.

Crosnoe, R. (2007). Early child care and the school readiness of children from Mexican immigrant families. The International Migration Review, 41, 152-181. https://doi.org/10.1111/j.1747-7379.2007. 00060.

Crosnoe R. \& Kalil, A. (2010). Educational progress and parenting among Mexican immigrant mothers of young children. Journal of Marriage and Family, 72, 976-990. https://doi.org/10.1111/J.17413737.2010.00743.

DeNavas-Walt, C., \& Proctor, B.D. (2015). Income and poverty in the United States: 2014, Table B-2, Current Population Reports, P60 252. Washington, DC: U.S. Department of Commerce, U.S. Census Bureau. Retrieved from http://www.census.gov/content/dam/ Census/library/publications/2015/demo/p60-252.pdf\#TableB-2 
Dozier, M., \& Bernard, K. (2017). Attachment and biobehavioral catchup: Addressing the needs of infants and toddlers exposed to inadequate or problematic caregiving. Current Opinion in Psychology, 15, 111-117. https://doi.org/10.1016/j.copsyc.2017.03.003.

Ellis, W. R., \& Dietz, W. H. (2017). A new framework for addressing adverse childhood and community experiences: The building community resilience model. Academic Pediatrics, 17(7), S86-S93.

Espinosa, L. M., \& Garcia, E. (2012). Developmental assessment of young dual language learners with a focus on kindergarten entry assessments: Implications for state policies. Working paper\# 1 . Center for early care and education research dual language learners (CECER-DLL): The University of North Carolina, Frank Porter Graham Child Development Institute Chapel Hill.

Federal Interagency Forum on Child and Family Statistics. (2014). America's children: Key national indicators of well-being, 2014, Table POP3. Washington, DC: Government Printing Office. Retrieved from http://www.childstats.gov/americaschildren/ tables. asp.

Felitti, V. J., Anda, R. F., Nordenberg, D., Williamson, D. F., Spitz, A. M., Edwards, V., et al. (1998). Relationship of childhood abuse and household dysfunction to many of the leading causes of death in adults: The adverse childhood experiences (ACE) study. American Journal of Preventive Medicine, 14(4), 245-258. https://doi.org/10. 1016/S0749-3797(98)00017-8.

Friese, S., Lin, V., Forry, N., \& Tout, K. (2017). Defining and measuring access to high quality early care and education: A guidebook for policymakers and researchers Washington, DC: OPRE.

Fuller, B., \& Garcia Coll, G. (2010). Learning from Latinos: Contexts, families, and child development in motion. Developmental Psychology, 46, 559-565. https://doi.org/10.1037/a0019412.

Galindo, C., \& Fuller, B. (2010). The social competence of Latino kindergartners and growth in mathematical understanding. Developmental Psychology, 46, 579-592.

Garcia Coll, C., Lamberty, G., Jenkins, R., McAdoo, H., Crnic, K., Wasik, B., \& Vazquez Garcia, H. (1996). An integrative model for the study of developmental competencies in minority children. Child Development, 67, 1891-1914.

Gennetian, L., \& Johnson, M. (2020). Work-based risks to Latino workers and their families from COVID-19. In Econofact Retrieved from https://econofact.org/work-based-risks-to-latinoworkers-and-their-families-from-covid-19.

Gennetian, L., Datta, A. R., Goerge, R., Zanoni, W., Brandon, R., Witte, A., \& Krishnamurty, P. (2019). How much of children's time in nonparental care coincides with their parents' time at work? Socius: Sociological Research for a Dynamic World, 5, 1-10. https://doi.org/10.1177/2378023119894848.

Goldenberg, C., Nemeth, K., Hicks, J., Zepeda, M., \& Cardona, L. (2013). Program elements and teaching practices to support young dual language learners. California's best practices for young dual language learners: Research overview papers, 90-118.

Gonzalez, L. M., Stein, G. L., Kiang, L., \& Cupito, A. M. (2014). The impact of discrimination and support on developmental competencies in Latino adolescents. Journal of Latina/o Psychology, 2(2), 79-91. https://doi.org/10.1037/lat0000014.

Gonzalez-Barrera (2015). More Mexicans leaving than coming to the U.S.: Net loss of 14,000 from 2009 to 2014. Family reunification top reason for return. Retrieved from https:/www.pewresearch.org/ Latino/2015/11/19/more-mexicans-leaving-than-coming-to-the-u-s/

Green, B. L., Ayoub, C., Bartlett, J. D., Furrer, C., Cohen, R. C., Buttita, K., Von Ende, A., Koepp, A., Regalbuto, E., \& Sanders, M. B. (2018). How early Head Start prevents child maltreatment. Retrieved from https://www.childtrends.org/publications/howearlyhead-start-prevents-child-maltreatment.

Griner, D., \& Smith, T. B. (2006). Culturally adapted mental health intervention: A meta-analytic review. Psychotherapy, 43(4), 531-548. https://doi.org/10.1037/0033-3204.43.4.531.
Guzman, L., Hickman, S., Turner, K., \& Gennetian, L. (2016). Latino children's participation in early care and education: Perceptions of care arrangements, and relatives' availability to provide care. Bethesda, MD: National Research Center on Latino Children \& Families. Retrieved online from http://www.Latinoresearchcenter. org/publications/Latino-childrens-participationin-early-care-andeducation-parents-perceptions-of-care-arrangements-and-relativesavailability-to-provide-care/.

Guzman, L. Ramos-Olazagasti, M.A., Miller, E. Padilla, C., Ryberg, R. \& Vega, C. (2018). How well do national surveys measure Latino families and households? National Research Center on Latino Children and Families. Bethesda: MD. Retrieved from https:// www.Latinoresearchcenter.org/wp-content/uploads/2019/08/ Latinos-Center-MHFL-brief_6.26-v21.pdf

Halgunseth, L., Ispa, J., \& Rudy, D. (2006). Parental control in Latino families: An integrated review of the literature. Child Development, $77,1282-1297$.

Hammer, C. S., Rodriguez, B. L., Lawrence, F. R., \& Miccio, A. W. (2007). Puerto Rican mothers' beliefs and home literacy practices. Language, Speech, and Hearing Services in Schools, 38(3), 216 224.

Harding, J. F., \& Paulsell, D. (2018). Improving access to early care and education: An equity-focused policy research agenda. Princeton, NJ: Mathematica Policy Research. Retrieved online from https:// www.mathematica-mpr.com/our-publications-and-findings/ publications/improving-access-to-early-care-and-education-anequity-focused-policy-research-agenda.

Hays-Grudo, J. (2020). Inaugural editorial. Adversity and Resilience Science https://doi.org/10.1007/s42844-020-00006-6, 1, 1, 4.

Hays-Grudo, J., Morris, A. S., \& American Psychological Association. (2020). Adverse and protective childhood experiences: A developmental perspective. American Psychological Association.

Helms, H., Hengstebeck N.D., Rodriguez, Y., Mendez, J.L. \& Crosby, D. (2015). Marriage as a context for children's development: The UNIDOS study of Mexican immigrant family life in a preemerging Southern gateway community. National Research Center for Latino Children and Families. http://www.childtrends.org/wpcontent/uploads/2015/09/Latino-Center-Unidos-Report.pdf

Hill, Z., Gennetian, L. A., \& Mendez, J. (2019). A descriptive profile of state Child Care and Development Fund policies in states with high populations of low-income Latino children. Early Childhood Research Quarterly, 47, 111-123. https://doi.org/10.1016/j.ecresq. 2018.10.003.

Johnson, A. D., Ruhm, C. J., Wen-Jui, H., \& Waldfogel, J. (2014). Child care subsidies and the school readiness of children of immigrants. Child Development, 85, 2140-2150.

Kane, M., Bailey, M., Wheat, J. \& Halle, T. (2020). Addressing adversity and supporting families and staff for success in Early Head StartChild Care partnerships. Child Trends. Retrieved online at https:// www.childtrends.org/publications/addressing-adversity-andsupporting-families-and-staff-for-success-in-early-head-start-childcare-partnerships

Lichter, D. T., Sanders, S. R., \& Johnson, K. M. (2015). Latinos at the starting line: Poverty among newborn infants in established gateways and new destinations. Social Forces, 94, 209-235.

Lieberman, A., Chu, A., Van Horn, P., \& Harris, W. W. (2011). Trauma in early childhood: Empirical evidence and clinical implications. Development and Psychopathology, 23, 397-410.

Lopez, M. H., \& Valasco, G. (2011). The toll of the great recession: Childhood poverty among Latinos set record, leads nation. Washington, DC: Pew Latino Center, Pew Research Center Retrieved at https://www.pewresearch.org/hispanic/2011/09/28/ childhood-poverty-among-hispanics-sets-record-leads-nation/.

Luthar, S. S., Cicchetti, D., \& Becker, B. (2000). The construct of resilience: A critical evaluation and guidelines for future work. Child Development, 71, 543-562. 
Magnuson, K., Lahaie, C., \& Waldfogel, J. (2006). Preschool and school readiness of children of immigrants. Social Science Quarterly, 85(5), 1241-1262.

Masten, A., \& Barnes, A. J. (2018). Resilience in children: Developmental perspectives. Children, 5, 98. https://doi.org/10. 3390/children5070098.

Matthews, H., Ulrich, R., \& Cervantes, W. (2018). Immigration policy's harmful impacts on early care and education. Washington, DC: Center for Law and Social Policy.

McKelvey, L. M., Conners Edge, N. A., Fitzgerald, S., Kraleti, S., \& Whiteside-Mansell, L. (2017). Adverse childhood experiences: Screening and health in children from birth to age 5. Families, Systems \& Health, 35, 420-429. https://doi.org/10.1037/ fsh0000301.

McNamara, K. (2016). Dual language learners in Head Start: The promises and pitfalls of new reforms. Retrieved from https://www. migrationpolicy.org/article/dual-language-learners-head-startpromises-and-pitfalls-new-reforms

McWayne, C. M., Melzi, G., Limlingan, M. C., \& Schick, A. (2016). Ecocultural patterns of family engagement among low-income Latino families of preschool children. Developmental Psychology, 52(7), 1088-1102. https://doi.org/10.1037/a0040343.

Mendez, J. (2018). Policy and practices to improve access to early care and education (ECE) for low-income Latino families. Bethesda, MD: National Research Center on Latino Children and Families http://www.Latinoresearchcenter.org/wp-content/uploads/2018/10/ Latino-Center-policy-and-practice-short-product-10.12.pdf.

Mendez, J. L., \& Crosby, D. (2018). Why and how do low-income Latino families search for early care and education (ECE)? (pp. 20182015). Bethesda, MD: National Research Center on Latino Children and Families. Brief http://www.Latinoresearchcenter.org/ wp-content/uploads/2018/05/Latinos-Center-parental-search-brief5.16-V2.pdf.

Mendez, J. L., \& Westerberg, D. (2012). Implementation of a culturally adapted treatment to reduce barriers for Latino parents. Cultural Diversity and Ethnic Minority Psychology, 18, 363-372. https:// doi.org/10.1037/a0029436.

Mendez, J. L., Westerberg, D. \& Thibeault, M.A. (2013). Examining the role of self-efficacy and communication as related to dimensions of Latino parent involvement in Head Start. NHSA Dialog: A Research-To-Practice Journal for the Early Childhood Field, 16(1), Special Issue on Parent Involvement and Engagement in Head Start, 65-80.

Mendez, J., Crosby, D., \& Siskind, D. (2018). Access to early care and education for low-income Latino children and families: A research synthesis. Bethesda, MD: National Research Center on Latino Children and Families http://www.Latinoresearchcenter.org/wpcontent/uploads/2018/09/Latinos-Center-ECE-Synthesis-Brief-9. 19.pdf.

Merritt, D. H., \& Klein, S. (2015). Do early care and education services improve language development for maltreated children? Evidence from a national child welfare sample? Child Abuse \& Neglect, 39, 185-196. https://doi.org/10.1016/j.chiabu.2014.10.011.

Morris, A. S., Treat, A., Hays-Grudo, J., Chesher, T., Williamson, A., \& Mendez, J. (2018). Integrating research and theory on early relationships to guide intervention and prevention. In A. S. Morris (Ed.), Building early relationships in infants and toddlers: Integrating social and emotional research and practice. Springer.

Murphey, D., Guzman, L. \& Torres, A. (2014). America's Latino children: Gaining ground, looking forward. Child Trends. Retrieved online at https://www.childtrends.org/wp-content/uploads/2014/09/ 2014-38AmericaLatinoChildren.pdf

National Academies of Sciences, Engineering, \& Medicine. (2017). Promoting the educational success of children and youth learning English: Promising futures. Washington, DC: National Academies Press.
National Research Council and Institute of Medicine (2000). From neurons to neighborhoods: The science of early childhood development. Committee on Integrating the Science of Early Childhood Development. In J.P. Shonkoff \& D A. Phillips (Eds.), Board on children, youth and families, commission on behavioral and social sciences and education. Washington, D.C.: National Academy Press.

National Study of Early Care and Education (2012). Retrieved online at https://www.norc.org/Research/Projects/Pages/national-survey-ofearly-care-and-education.aspx

Paschall, K. \& Mastergeorge, A.M. (2016). Opportunities for Early Head Start to buffer infants and toddlers from toxic stress. Retrieved online at https://www.apadivisions.org/division37/publications/ newsletters/maltreatment/2016/12/

Passel, J. S., Cohn, D., \& Gonzalez-Barrera, A. (2012). Net migration from Mexico falls to zero - and perhaps less. Washington, DC: Pew Latino Center Retrieved from http://www.pewLatino.org/files/2012/ 04/Mexican-migrants-report final.pdf.

Raikes, H. H., Vogel, C., \& Love, J. M. (2013). Family subgroups and impacts at ages 2,3 , and 5 : Variability by race/ethnicity and demographic risk. Monographs of the Society for Research in Child Development, 78, 64-92. https://doi.org/10.1111/j.1540-5834. 2012.00703.x.

Ramos-Olazagasti, M. A., Bird, H. R., Canino, G., \& Duarte, C. S. (2017). Childhood adversity and early initiation of alcohol use in two representative samples of Puerto Rican youth. Journal of Youth and Adolescence, 46(1), 28-44. https://doi.org/10.1007/s10964016-0575-2.

Reese, L., Balzano, S., Gallimore, R., \& Goldberg, C. (1995). The concept of educación: Latino family values and American schooling. International Journal of Educational Research, 23, 57-61.

Sandstrom, H. \& Huerta, S. (2013). The negative effects of instability on child development. Urban. Retrieved online at https://www.urban. org/sites/default/files/publication/32706/412899-The-NegativeEffects-of-Instability-on-Child-Development-A-ResearchSynthesis.PDF

Schmit, S \& Walker, C. (2016). Disparate access: Head Start and CCDBG data by race and ethnicity. CLASP. Retrieved online at https://www.clasp.org/sites/default/files/public/resources-andpublications/publication-1/Disparate-Access.pdf

Shonkoff, J., Garner, A.S., and the committee on psychosocial aspects of child and family health, committee on early childhood, adoption, and dependent care, and section on developmental and behavioral pediatrics. (2012). Technical report: The lifelong effects of early childhood adversity and toxic stress. Pediatrics, 129(1), e232e246. https://doi.org/10.1542/peds.2011-2663.

Singer, A. (2008). Twenty-first-century gateways: An introduction. In A. Singer, S. W. Hardwick, \& C. Brettell (Eds.), Twenty-first century gateways: Immigrant incorporation in suburban America (pp. 330). Washington, DC: Brookings Institution Press.

Slopen, N., Shonkoff, J. P., Albert, M. A., Yoshikawa, H., Jacobs, A., Stoltz, R., \& Williams, D. R. (2016). Racial disparities in child adversity in the U. S.: Interactions with family immigration history and income. American Journal of Preventive Medicine, 50, 47-56. https://doi.org/10.1016/j.amepre.2015.06.013.

Stein, G. L., Cupito, A., Mendez, J. L., Prandoni, J., Huq, N., \& Westerberg, D. (2014). Familism through a developmental lens. Journal of Latina/o Psychology, 2, 1-27. https://doi.org/10.1037/ lat0000025.

Thibeault, M., Mendez, J. L., Nelson-Gray, R., \& Stein, G. (2017). Impact of trauma exposure and acculturative stress on internalizing symptoms for recently-arrived migrant-origin youth: Results from a community-based partnership. Journal of Community Psychology, 45, 984-998. https://doi.org/10.1002/jcop.21905.

Turner, K., Wildsmith, E., Guzman, L., \& Alvira-Hammond, M. (2016). The changing geography of Latino children and families (Brief 
\#2016-06). Bethesda, MD: National Center for Research on Latino Children and Families.

U.S. Department of Health and Human Services. (2014). Survey data elements to unpack diversity of Latino populations (OPRE Report \#2014-30). Washington, DC: Office of Planning, Research and Evaluation, Administration for Children and Families, U.S. Department of Health and Human Services.

U.S. Government Accountability Office. (2016). Access to subsidies and strategies to manage demand vary across states (GAO-17-60). Retrieved from: https://www.gao.gov/products/GAO-17-60

Van Hook, J., \& Glick, J. E. (2020). Spanning borders, cultures, and generations: A decade of research on immigrant families. Journal of Marriage and Family, 82, 224-243. https://doi.org/10.1111/jomf. 12621.

Vesely, C. K., Ewaida, M., \& Kearney, K. B. (2013). Capitalizing on early childhood education: Low-income immigrant mothers' use of early childhood education to build human, social, and navigational capital. Early Education \& Development, 24(5), 744-765.

Vesely, C. K., Goodman, R. D., Ewaida, M., \& Kearney, K. B. (2015). A better life? Immigrant mothers' experiences building economic security. Journal of Family and Economic Issues, 36(4), 514-530.

Votruba-Drzal, E., Coley, R. L., Collins, M., \& Miller, P. (2015). Centerbased preschool and school readiness skills of children from immigrant families. Early Education and Development, 26(4), 549-573.

Weber, R. B. (2011). Understanding parents' child care decision-making: A foundation for child care policy making: Office of Planning, Research and Evaluation.
Wildsmith, E., Ramos-Olazagasti, M, \& Alvira-Hammond, M (2018). The job characteristics of low-income Latino parents. National Research Center on Latino Children and Families. Retrieved online at https://www.Latinoresearchcenter.org/wp-content/uploads/2019/ 08/Latinos-Center-Employment-Profiles-FINAL1.pdf

Yazejiana, N., Bryant, D., Freel, K., Burchinal, M., \& the Educare Learning Network (ELN) Investigative Team. (2015). Highquality early education: Age of entry and time in care differences in student outcomes for English-only and dual language learners. Early Childhood Research Quarterly, 32, 23-39.

Yoshikawa, H., Kholoptseva, J., \& Suarez-Orozco, C. (2013). The role of public policies and community-based organizations in the developmental consequences of parent undocumented status. Social Policy Report, 27(3), 1-17. From http://www.srcd.org/sites/default/files/ documents/spr 27_3.pdf

Zaslow, M., Crosby, D. A., \& Smith, N. (2013). Issues of quality and access emerging from the changing early childhood policy context: Toward the next generation of research. In E. T. Gershoff, R. S. Mistry, \& D. A. Crosby (Eds.), Societal contexts of child development: Pathways of influence and implications for policy and practice. Oxford: New York, NY.

Zayes, L., \& Pilat, A. M. (2008). Suicidal behavior in Latinas: Explanatory cultural factors and implications for intervention. Suicide Life Threatening Behavior, 38(3), 334-342. https://doi.org/ 10.1521/suli.2008.38.3.334

Zero to Three. (2020). How Covid-19 is impacting child care providers. Retrieved online at https://zero-to-three.s3.amazonaws.com/ documents/ 